\title{
Research Insights from a Decade of Campus-Wide Implementation of Web-Supported Academic Instruction at Tel Aviv University
}

\author{
Rafi Nachmias and Judith Ram \\ Tel Aviv University
}

\begin{abstract}
This paper describes the scope and outcomes of Virtual TAU, a campus-wide project that aims to integrate information and communication technologies into the academic instruction at Tel Aviv University (TAU). It provides data, insights, and conclusions drawn from various research and evaluation studies that were conducted at the university during the last decade. The paper presents its material on three main levels: (a) the institutional level, in which we describe the scope and pace of the process of diffusing the Web as an innovation into the university's instruction, and how this diffusion compares to classical diffusion models; (b) the pedagogical level, in which we present some of the innovative pedagogical practices developed and implemented as well as the current state of Web usage among both the university's teachers and students; and (c) the costs and benefits of the integration of Web-supported academic instruction, where we apply a newly-developed costeffectiveness model to Virtual TAU courses.
\end{abstract}

Keywords: Web-supported academic instruction; empirical research; diffusion of innovation; Web pedagogy; cost-effectiveness model

\section{Introduction}

Online learning has become widely popular in academic institutions in the last decade. University leaders and administrators are aware of the pedagogical and economical potential of using advanced technologies and of their possible role in changing the structure of academic instruction. They believe that Web-supported instruction should be included as part of a university's long-term strategy (Bates, 2000; Allen \& Seaman, 2005, 2006, 2007). Many lecturers who are now in the process of integrating the Internet in their instruction are using various Web-supported learning environments that facilitate more flexible and effective instruction. Tel Aviv University was amongst the pioneers in this trend about a decade ago, accompanying the implementation with ongoing research and evaluation (Nachmias, 2002). Lecturers first started to use the Internet in their instruction in 1998, and in the academic year 2000-01, a campus-wide project was launched in order to facilitate the integration of information and communication technologies into the academic instruction of the entire university. This paper describes the project's scope and outcomes and provides some data and insights from the 
various research and evaluation studies conducted in recent years. The paper relates to three main levels: the institutional level, in which we present the scope and pace of the process whereby the Web as an innovation was diffused into the university's instruction; the pedagogical level, in which we present the innovative pedagogical practices developed and implemented by some instructors as well as the current state of Web usage in all instruction at TAU; and, finally, the level of the costs and the benefits of the integration of Web-supported academic instruction.

\section{The Virtual TAU Project}

Tel Aviv University (TAU) is one of the largest research-oriented universities in Israel. Located in the center of the country, it serves some 26,000 students. These students are enrolled in about 6,000 courses annually, which are taught by about 2,000 instructors in almost every academic discipline. The Virtual TAU project (see http://virtual.tau.ac.il) was launched in the academic year 2000-01, following a government initiative to advance the implementation of learning technologies in Israeli higher education. The project aimed to initiate and stimulate a process by which more faculty members would gradually come to use the Internet to enrich prevailing learning processes and to make traditional instruction more efficient and flexible. The learning management system (LMS) used by Virtual TAU is Highlearn, a multilingual Internet course management system developed by Britannica Knowledge Systems. Highlearn, similar to other LMSs (e.g., Blackboard, Moodle), allows the easy creation of an information base for the course's content and didactic activities and supplies asynchronous communication tools (e.g., forums) for students and instructors. In addition, it provides tools that assist instructors in administrating courses (e.g., course scheduler, test builder, address book).

One fundamental principle of Virtual TAU is that the instructors, most of them TAU faculty members, maintain full responsibility for their course Web sites. Their views regarding the objectives, syllabus, and instructional methods lead to both development and implementation of the course Web site. No pre-designed pedagogical solution was imposed; rather, each instructor acts according to his or her own pedagogical approach. Most of the projects' activities aim to empower the instructors and to help them realize their pedagogical vision (Bates, 2000; Nachmias, Ram, \& Mioduser, 2006).

One of the conditions for accepting government funding was to create and maintain a central support center at the university as it was clear that the success of the process would depend on intensive support for the instructors. The center provides conceptual, pedagogical, and technical support for the instructors, via workshops, online tutorials, one-to-one meetings, and a helpdesk (serving both instructors and students). Technological aspects, such as server maintenance, integrating the Virtual TAU Web shell with the university's computation services and data bases, and video recording of lectures, are the responsibility of the university's Information Technology and Computing Division.

A major objective of Virtual TAU is to investigate and evaluate the learning potential embedded in typical Web-supported courses and to examine the conditions for realizing this potential. A research framework for the study of campus-wide academic instruction using the Web was described in detail by Nachmias (2002). This framework consists of three levels: (a) the macro level, which focuses on the diffusion process of the Internet in university instruction from the institutional perspective; (b) the mezzo level, which focuses on the emergence of new pedagogies and learning paradigms in courses that integrate the Web into traditional instruction; and (c) the micro level, which concerns the actual use of the Web in the teaching and learning process of specific courses. Graduate students from the 
School of Education at TAU at both the MA and $\mathrm{PhD}$ levels are involved in this research agenda. This paper is an attempt to highlight some of the findings and insights, mainly on the macro and mezzo levels.

\section{The Integration of Web-Supported Instruction in TAU: The Institutional Level}

A first descriptive measure of the process on the institutional level is the number of courses and lecturers that joined the project during the last eight years. This does not reveal the whole picture but one important part of it. Figure 1 presents the number of academic courses that were a part of the Virtual TAU project during the years 2000-01 - 2007-08. The graph indicates that the number of such courses increased more than tenfold over the eight year period: from 346 courses in 2000-01 to 4,395 courses in 2007-08. It should be noted that at the start of the academic year 2000, only ninety instructors showed an interest in the project and submitted proposals for developing Web sites for about 100 courses. Soon after the opening of the support center it became clear that the demand for Virtual TAU's services was way beyond expectations. Consequently, it was decided to enable all instructors to join the project and to receive the center's support as needed. As a result, many more instructors joined the project and by the end of the first year there were about 350 course Web sites. This number almost tripled in the second year (1,036 courses), doubled in the third year $(2,138$ courses), and once again in the consecutive three years (4,038 courses); and since then, the number of courses has been growing slowly to the current number of 4,395 courses, of the about 6,000 courses offered by Tel Aviv University annually. Moreover, in the 2007-8 academic year, the log counter shows over 8,000,000 entries for over 155,000 Web learning items by about 24,000 students (almost all TAU students) and 193,000 course enrollments.

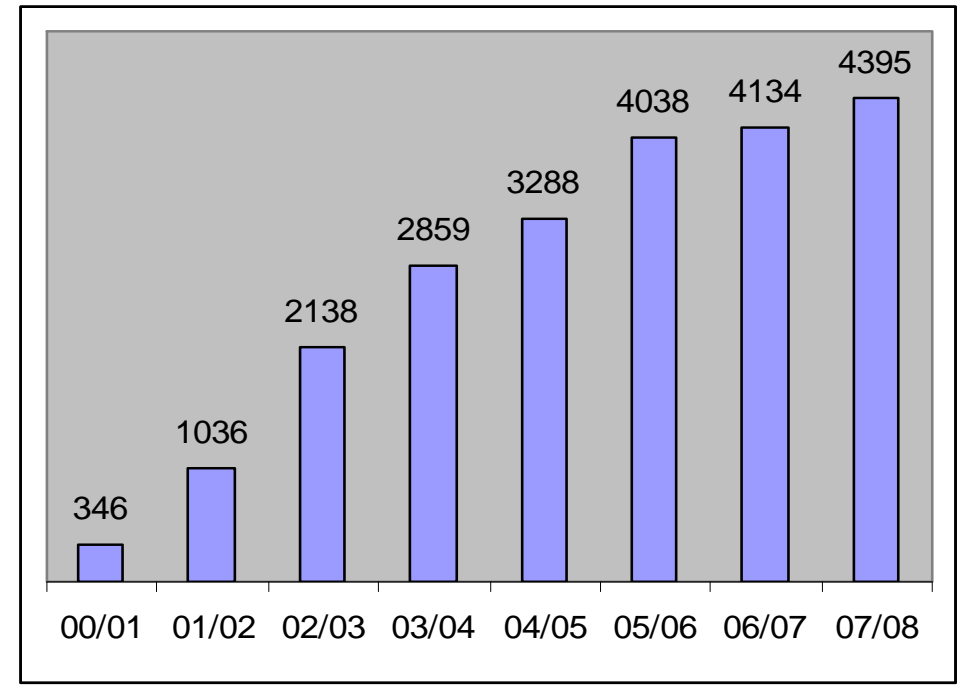

Figure 1. Number of courses using Virtual TAU in the academic years 2000-01 2007-08.

This phenomenon raised questions about the characteristics of the diffusion process of Web-supported instruction at TAU from the instructors' points of view: Does the diffusion process match existing diffusion models of technological innovation, e.g., Rogers (1995) and Bass (1969)? And when does the process reach the compensation level? These questions (among others) were asked and answered in a PhD thesis (Soffer, 2006) and will be described here briefly. 
Rogers, in his book Diffusion of Innovation (1995), defines innovation as an idea, object, or practice that is perceived as new by the individual or organization. The innovation may be perceived differently among individuals, and the time it takes for individuals to adopt the innovation may be different. Diffusion, furthermore, is defined as the process by which an innovation is communicated through certain channels among the members of a social system over time. Rogers claims that innovations tend to spread through society in an S-shaped curve, with early adopters selecting the technology first, followed by the majority, until a technology or innovation is considered common. He explains that innovations are initially perceived as uncertain and even risky. To reduce the uncertainty, most people look for others like themselves who have already adopted the new idea and gained some experience. Rogers (in the latest edition of his book Diffusion of Innovation, 2003) argues that the penetration of the Internet into our daily life has sped up the diffusion of Websupported learning. Rogers (1995) presented a classification scheme of potential adopters of innovation based on their receptivity: innovators (2.5\%), who are the risk takers willing to take the initiative and time to try something new; early adopters (13.5\%), who tend to be respected group leaders and are essential to adoption by the whole group; early majority (34\%), who are the careful, safe, deliberate individuals unwilling to risk time or other resources; late majority (34\%), who are those suspicious of or resistant to change. Finally there are those who are hard to move without significant influence and laggards (16\%), who are consistent or even adamant in resisting change.

An analysis of TAU's diffusion process among instructors each semester during the years 2000-01 2004-05 is presented in Figure 2. The rate of diffusion of Virtual TAU among instructors was rapid, starting from 70 instructors during the first semester of the first academic year (2000-01) and rising to 1,296 instructors at the end of the second semester of the fifth academic year (2004-05). The percentage of instructors using Virtual TAU from the total number of senior and junior instructors at the university (1,558 to 1,735 during these years) increased from $5 \%$ at the beginning to $75 \%$ at the end of the fifth academic year (2004-05). In terms of Roger's model, the innovators were there before the project started, initiating it in 2000-01. The early adopters joined the process as early as the second year, the early majority in the third year, and the late majority during the fourth and fifth years. This represents a very rapid adoption process of Web-supported instruction among TAU instructors.

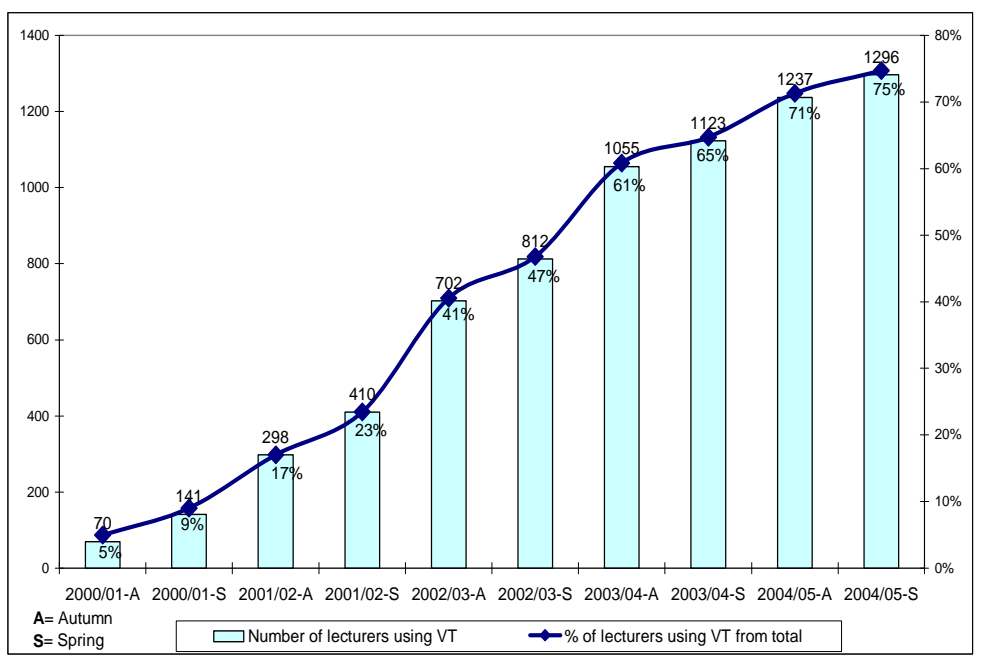

Figure 2. Growth rate in the number of instructors using Virtual TAU.

It seems that the number of instructors using the Internet reached its compensation level in the fifth year of the project. About $20 \%$ of the potential population of instructors does not "join the 
bandwagon,” as proposed in another study (Elstein, 2004), either because of the time investment required and their doubts concerning the added value of the Internet or because they are using other methods of publishing their course contents on the Web. Significant differences were found in the Virtual TAU diffusion process among instructors in different academic units. Further discussion of these differences is beyond the scope of this paper and can be found elsewhere (Soffer \& Nachmias, 2008).

Bass's (1969) Diffusion Model is one of the best known models in the field of marketing. It allows us to estimate the number of potential Virtual TAU adopters in the university by providing a mathematical formula. The model assumes that potential adopters of an innovation are influenced by two types of communication channels: the mass media and interpersonal channels. As for the diffusion process, more weight is given to interpersonal communications. Bass assumes that the diffusion process will be S-shaped, whereby the rate of adoption during the first half of the diffusion process is symmetrical with that in the second half. His model consists of three key elements: (1) $p=$ the innovators, adopters who have been influenced by the media; (2) q = imitators, adopters who have been influenced by interpersonal communication and (3) $\mathrm{m}=$ the market potential for the innovation. When these three parameters are known we can forecast the potential innovation over time. If the curve is S-shaped, it means that q is higher than $\mathrm{p}$, and the product is innovative. If the curve takes a $\mathrm{J}$-shape, $\mathrm{q}$ is smaller than $\mathrm{p}$, and the product is less innovative and does not involve high risk. The values of the parameters $\mathrm{p}$ and $\mathrm{q}$ affect the speed of the diffusion process.

Figure 3 presents the results of Bass's diffusion model of Virtual TAU among instructors at the university between the academic years 2000-01 - 2006-07. The results of the analysis show that $\mathrm{m}=$ $0.75, \mathrm{p}=0.032$ and $\mathrm{q}=0.558$. A possible way to understand these figures is to compare them to the same analysis done for cellular telephone diffusion over a period of ten years in which $\mathrm{m}=0.45, \mathrm{p}=$ 0.008 and $q=0.427$. These figures suggest that the percentage of instructors at the university who will use Virtual TAU may reach up to 75\%. It also means that Virtual TAU is perceived as an innovative product among instructors at TAU. Looking at the values $\mathrm{p}$ and $\mathrm{q}$, we could say that the diffusion process developed fast initially and then slowed down. These results show that the diffusion process was mainly affected by the imitators, who were influenced by interpersonal communication (mostly peers and/or colleagues). The innovators had a much smaller effect on the diffusion process of Virtual TAU.

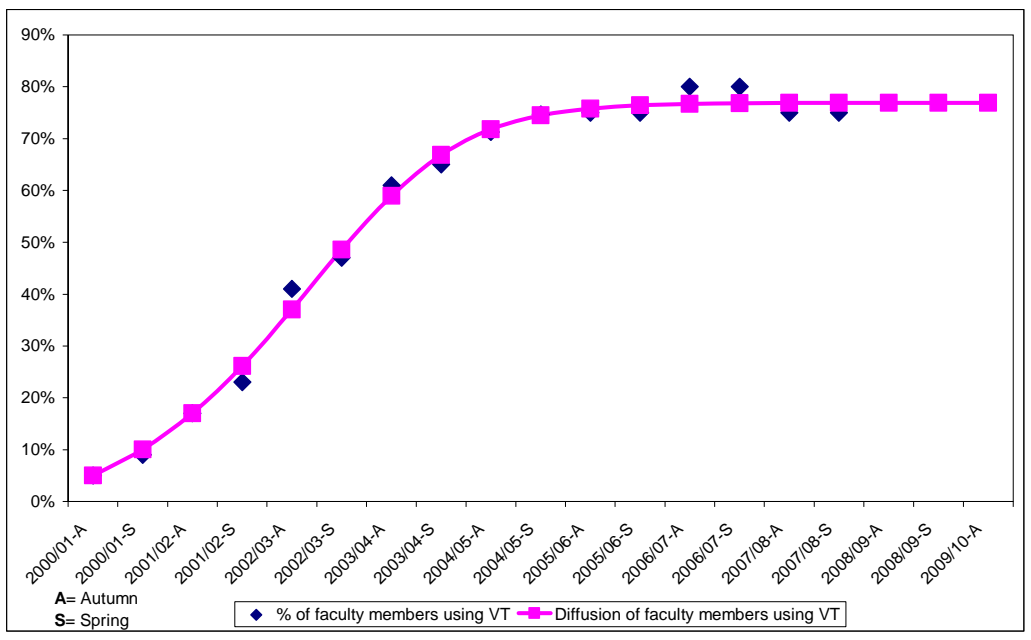

Figure 3. Virtual TAU diffusion model among instructors according to Bass's diffusion model. 
In sum, we learn from this study that the diffusion process of Web-supported academic instruction at TAU is very similar to the classical models of innovation diffusion, representing very fast adoption.

\section{Pedagogical Aspects}

The integration of Web-supported learning at TAU was clearly rapid. However, it is even more interesting to educators to understand the pedagogical aspects of this usage and whether, as a result, novel pedagogical models and approaches are emerging. Our understanding of the emergent Web pedagogy is twofold: on one hand, we seek illustrations of the feasibility of using the Web in such a way that its potential benefits and promises are fulfilled. Our questions from this perspective are as follows: Can we really increase instructional flexibility, improve learning efficiency, and augment the quality and richness of academic instruction? If the answer is yes then the question is in what ways? On the other hand, we know that not all lecturers are using the Web equally, in terms both of exploiting its innovativeness and of time investment. Given this situation, the questions are these: What are the lecturers using the Web for and to what extent?

In order to address these pedagogical issues we undertook two different types of studies: the first was a series of case studies of specific, Web-based, innovative pedagogical practices at TAU and the second included another series of studies mapping and analyzing the use of the Web by all TAU instructors and students.

The series of case studies of campus-wide, Web-based, innovative pedagogical practices was conducted in the years 2005-2007. The study was funded by the Israeli Council for Higher Education with the aim to develop and assess innovative pedagogical models and to prove the feasibility of fulfilling the Web's potential. Instructors throughout the campus were encouraged to submit a proposal to develop, implement, and assess a Web-based pedagogical innovation in their course. Thirteen of the submitted courses were chosen, and they were mainly large courses or special learning objects that could be transferred and reused in other similar units or other academic institutions. A hidden concern of the study was to check the possibility of reducing expenses in the long run. Each one of the 13 lecturers received a small grant for two years (ranging from \$15,000 - \$85,000). Altogether, the cost for the project was $\$ 450,000$. Table 1 presents the 13 courses with a short description of the pedagogical models that were developed and experimented with.

Table 1

Case Studies of Campus-Wide, Web-Based, Innovative Pedagogical Practices

\begin{tabular}{|c|c|c|c|}
\hline THE MODEL & COURSE NAME & DEPARTMENT & $\begin{array}{l}\text { NO. OF } \\
\text { STUDENTS }\end{array}$ \\
\hline \multirow{3}{*}{$\begin{array}{l}\text { Fully Online Courses - Fully } \\
\text { online courses have almost no } \\
\text { face-to-face interaction and the } \\
\text { course content, assignments, and } \\
\text { communications are dealt with on } \\
\text { the Internet. }\end{array}$} & $\begin{array}{l}\text { Principles of Marketing } \\
\text { Management }\end{array}$ & Management & 200 \\
\hline & Statistics for Economists & Social Sciences & 400 \\
\hline & Statistics for Psychologists & Social Sciences & 300 \\
\hline Online Exercise Repositories - & Introduction to Cell Biology & Life Sciences & 520 \\
\hline
\end{tabular}




\begin{tabular}{|c|c|c|c|}
\hline \multirow[b]{2}{*}{$\begin{array}{l}\text { The course Web sites serve as } \\
\text { online exercise repositories and } \\
\text { contain interactive self testing } \\
\text { and assessment with immediate } \\
\text { feedback, which enables } \\
\text { individual learning at a personal } \\
\text { pace. }\end{array}$} & Physiological Psychology & Social Sciences & 300 \\
\hline & $\begin{array}{l}\text { Introduction to Ottoman } \\
\text { Empire }\end{array}$ & Humanities & 120 \\
\hline \multirow{2}{*}{$\begin{array}{l}\text { Case Studies - The course Web } \\
\text { sites contain case studies, which } \\
\text { are discussed and analyzed by the } \\
\text { students on the Web. }\end{array}$} & $\begin{array}{l}\text { Assessment and } \\
\text { Rehabilitation of Driving } \\
\text { Skills }\end{array}$ & $\begin{array}{l}\text { School of health } \\
\text { professions }\end{array}$ & 20 \\
\hline & $\begin{array}{l}\text { Clerkship in Family } \\
\text { Medicine }\end{array}$ & Medicine & 100 \\
\hline $\begin{array}{l}\text { Distant Laboratory Use - The } \\
\text { course Web site gives students } \\
\text { Web access to hardware and } \\
\text { software components physically } \\
\text { installed in the real lab. }\end{array}$ & $\begin{array}{l}\text { Computer Integrated } \\
\text { Manufacturing Lab }\end{array}$ & Engineering & 120 \\
\hline \multirow{2}{*}{$\begin{array}{l}\text { Databases - the course Web site } \\
\text { is a structured collection of } \\
\text { textual and graphical data } \\
\text { accompanied by metadata. }\end{array}$} & Plants Anatomy Laboratory & Life Sciences & 250 \\
\hline & $\begin{array}{l}\text { Introduction to Technology } \\
\text { in Occupational Therapy }\end{array}$ & $\begin{array}{l}\text { School of Health } \\
\text { Professions }\end{array}$ & 100 \\
\hline $\begin{array}{l}\text { Online Assignment Submission } \\
\text { System - Web-based module that } \\
\text { allows students to submit their } \\
\text { work through the Web and to } \\
\text { receive the instructor's feedback. }\end{array}$ & Programming & Exact Sciences & 275 \\
\hline $\begin{array}{l}\text { Simulations - The course Web } \\
\text { site is an interactive learning } \\
\text { environment based on } \\
\text { simulations. The simulations are } \\
\text { interactive software, which assists } \\
\text { the student in understanding } \\
\text { complex processes. }\end{array}$ & $\begin{array}{l}\text { Introduction to } \\
\text { Geoinformatics }\end{array}$ & Humanities & 130 \\
\hline
\end{tabular}

In each of these 13 courses the pedagogical concept and materials were developed over a period of one to two years, and they were implemented at least once (during one semester or one year). The case studies were conducted during this experimental implementation, and they included computer usage log analysis, student attitude assessments via questionnaire, and long interviews with the instructors and some students. A detailed description of these case studies is naturally not in the scope of this paper. However, we can conclude that pedagogical models developed by teams headed by the instructors were impressive, and each one of them provided a useful example of how the Web's potential may be fulfilled. We also found that the students were highly satisfied with the new technological developments, especially with the fully online courses and the models that increase the flexibility of the learning process. Major problems encountered were the sustainability and transferability of these innovative models. Since the instructors were not paid and hardly rewarded for their efforts, they tended to invest a good deal of time to begin with but then did not sustain the effort 
needed to update their developments. Transfer of these innovations to other lecturers and universities was barely achieved. A central effort of TAU or even at the nationwide level is needed in order to realize the potential for cooperation among departments in Tel Aviv University and other universities in the country that are teaching the same subjects and in some cases might even develop similar projects.

A series of studies conducted at TAU during 2002-2007 assessed the current state of all instructors' implementation of their Web sites and students' consumption and usage of these Web sites. Six of these studies are described here briefly.

Shemla (2008) provides a comprehensive view of the current state of instructors' usage of the Web. The research was implemented at TAU in order to investigate the purposes and extent of Internet integration into teaching and learning processes (e.g., content delivery, learning activities, and course management) by all instructors. Courses examined included all course Web sites that were created and implemented by faculty within the Virtual TAU framework upon completion of the autumn semester of the 2002-03 academic year. A total of 202 Web sites were randomly selected as research subjects, representing all TAU academic units. Each Web site was analyzed according to the course Web site characterization scheme that was developed for this study (Shemla \& Nachmias, 2007). This tool consists of four instructional dimensions, content delivery, learning activities, course management, and learning flexibility, and it characterizes the Web sites' pedagogical usage. During this procedure, 6,507 valid Web items were categorized and analyzed, and data were collected on the Web site structure and navigation tools. In addition, each Web site was graded, indicating the extent of the realization of its pedagogical potential, i.e., to what extent does the Web site exploit the media's advantages?

The purpose and extent of usage in all analyzed course Web sites, with reference to content delivery, learning activities, and management are presented in Table 2. The second column presents the number of items found in each category and column 3 presents their percentage in relation to all items $(N=$ 6,507). The fourth column presents the percentage of Web sites at which these items were found $(N=$ 202). These data reveal that $73 \%$ of all items were aimed at content delivery, e.g., syllabus, digital articles, and presentations; $22 \%$ of all items included learning activities, and only 5\% were instructor's messages regarding course management. While $100 \%$ of the courses had at least one content item, learning activities were found in only $60 \%$ of the courses, and course management items were found in $70 \%$ of the courses.

Table 2

Purpose and Extent of Web Usage $(N=202$ Course Web Sites $/ N=6,507$ items $)$

\begin{tabular}{||l|l|l|l||}
\hline PURPOSE OF & $\begin{array}{l}\text { NUMBER } \\
\text { OF ITEMS }\end{array}$ & $\begin{array}{l}\text { PERCENTAGE } \\
\text { OF } \\
\text { ALL ITEMS } \\
N=6507\end{array}$ & $\begin{array}{l}\text { PERCENTAGE } \\
\text { OF } \\
\text { COURSE } \\
\text { WEBSITES } \\
N=202\end{array}$ \\
& & 73 & 100 \\
\hline Content delivery & 4,738 & 22 & 60 \\
\hline Learning activity & 1,440 & 5 & 70 \\
\hline Management & 329 & 5 & \\
\hline
\end{tabular}




\begin{tabular}{|l|l|l|l||}
\hline Total & 6,507 & 100 & \\
\hline
\end{tabular}

Another finding of this study was that the most common Web use was not for distance learning but for augmenting traditional instruction with supporting course Web sites. None of the sampled instructors chose to deliver their courses in an exclusively online version without face-to-face interaction. Only three of the courses reviewed (1.5\%) replaced face-to-face meetings with an equivalent number of virtual ones (blended learning as defined by Bonk \& Graham, 2006), and only in six courses were Web activities considered part of the final course grade.

Considering the types of learning modes supported, the results show that while all course Web sites support students' individual work, only $19 \%$ of them contain activities that support whole-class interaction (e.g., via an online discussion forum), and only $1.5 \%$ of the Web sites implement collaborative learning in small work groups.

The results of assessing the use of non-textual representation on the course Web site (e.g., still or dynamic image, animation, simulation, sound, and video) are represented in Table 3. The table reveals the minor use of non-textual representation. Furthermore, the use of video or sound files was rare. We assume that this situation is subject to change due to increased bandwidth and to Web 2.0 applications that facilitate user-developed content and knowledge sharing (e.g., YouTube, Flickr).

Table 3

Representational Means Frequency ( $N$ = 202 Course Web sites)

\begin{tabular}{||ll|l|l|l|l|l|l||}
\hline EXTENT OF USE & $\begin{array}{l}\text { IMAGE } \\
(\mathbf{\%})\end{array}$ & $\begin{array}{l}\text { SIMULATION } \\
(\mathbf{\%})\end{array}$ & $\begin{array}{l}\text { SKETCH } \\
\mathbf{( \% )}\end{array}$ & $\begin{array}{l}\text { GRAPH } \\
\mathbf{( \% )}\end{array}$ & $\begin{array}{l}\text { VIDEO } \\
\mathbf{( \% )}\end{array}$ & $\begin{array}{l}\text { SOUND } \\
\mathbf{( \% )}\end{array}$ \\
\hline Not at all & & 87.1 & 96.0 & 83.7 & 85.6 & 99.0 & 98.5 \\
\hline $\begin{array}{l}\text { Seldom } \\
\text { items }\end{array}$ & $(1-10$ & 4.0 & 0.5 & 2.5 & 1.5 & 1.0 & 1.5 \\
\hline $\begin{array}{l}\text { Medium } \\
\text { items }\end{array}$ & $(11-25$ & 1.5 & - & 6.9 & 7.4 & - & - \\
\hline $\begin{array}{l}\text { Frequent } \\
\text { items }\end{array}$ & $(25+$ & 7.4 & 3.5 & 6.9 & 5.5 & - & - \\
\hline
\end{tabular}

Use of interactivity was another focus of this research. Each of the 1,440 activity items was placed in one of four interaction categories: student-software, student-content, student-student and studentinstructor. The most frequent interaction was between student and software, e.g., simulations or online exercises with immediate feedback ( $42.6 \%$ of the items). Interaction between the student and the learning materials (e.g., written assignments) occurred in $38.3 \%$ of the items. Surprisingly, interaction between student and instructor appeared in $12.2 \%$ of the items and between students (e.g., via an asynchronous forum) in only $7.0 \%$ of them.

From this study we can conclude that realization of the Web's potential was limited as well. Maximum flexibility (Collis \& Moonen, 2001) in learning time and space was hardly achieved. None of the instructors (in our sample) created fully online courses and very few replaced face-to-face meetings in classes with virtual ones. In the vast majority of the courses, Web activities came as an addition to the classes and in some cases increased the workload of both students and instructors. 
Other as yet unrealized potentials are related to the representational means. Sophisticated, high-level media is perhaps one of the defining characteristics of Web sites today. However, instructors refrained from taking the pedagogical advantage of enriching the learning materials in a multi-sensory way. Similarly, our research showed poor results concerning Web site interactivity. Although the research literature has high expectations regarding the growth of interaction between participants, this study shows that in our case most interaction occurred between students and software and/or learning Page | 10 materials. Collaboration and peer interaction were rare.

Use of the course Web sites was the subject of several studies. The first one, conducted in 2002, aimed to understand TAU students' use of content in Web-supported academic courses and analyzed students' logs in 117 Web-supported courses (Nachmias \& Segev, 2003). It was found that about half of the courses had items which none of the students viewed. In addition, results showed that each item was viewed by an average of only $28 \%$ of the enrolled students. Moreover, $55 \%$ of the items were visited by less than a quarter of the students, and only $16 \%$ of the items gained the attention of over half of the students. No content item was found to have been accessed by all students. This means that though the Web site hypothetically exposes the students to a variety of contents, the students may not view them. Three other studies exploring students' participation patterns in Web-supported academic forums at TAU (Acrich, 2005; Tikochinsky, 2002; Steimberg, Ram, Nachmias, \& Eshel, 2006) show that it is not obvious that students will participate in forums unless participation is obligatory or perceived by the students as beneficial to their success in the final examination.

The last study reported here was a controlled experiment aimed at evaluating the effectiveness of a redesigned fully online course, Introduction to Statistics for Economists, by comparing it to blended learning (face-to-face lectures and online exercise sessions) and face-to-face versions of the same course $(N=151)$ (Steimberg, Ram, Nachmias, \& Israeli, 2008). It also aimed to evaluate the usefulness of Web-based technological applications when they were integrated into the redesigned fully online course. The findings indicate that student achievements, attitudes, and satisfaction in the redesigned fully online course were similar to those in the face-to-face course. As regards the usefulness of the technological components, the study reveals that students make extensive use of some mandatory components, which they assume might help them succeed in the final examination; they do not take as much advantage of other components, such as applets, which support in-depth understanding of statistical concepts.

\section{Cost and Benefit Analysis}

The third issue highlighted in this paper is the cost and benefit of Web-supported learning from both the economical and educational perspectives. More and more universities and educational institutions are considering the integration of new information technologies in their instruction. However, not many of them are fully aware of the complexity of this process, nor do they recognize what their decision-making really involves. The relevant considerations are twofold: the long-term policy level and the level of the online instructor. This mission is even more difficult and confusing considering the wide variety of distance and online learning models and strategies implemented in diverse settings, from Web-supported academic instruction through blended learning and up to a fully online model. Therefore, economic planning, costing, decision-making management, cost effectiveness, and cost-benefit analysis are essential components in this process. 
In light of these issues, a comprehensive model was developed, validated, and implemented at TAU in the year 2007-08. This study is part of a PhD research project (Cohen, 2009) and a few of its highlights will be provided here.

The model consists of the following: (a) a cost effectiveness framework that defines cost and benefit components of Web-supported academic instruction and (b) a computational analyzer that provides a Page | 11 translation of the components into quantitative values (full details in Cohen \& Nachmias, 2006). For this purpose a different measure for each of the components was developed enabling calculation and quantification in relation to each of the three main actors involved in the learning-teaching process: students, instructors, and the university. The model validation was conducted with reference to theoretical and experimental literature, experts in Web-supported academic instruction, and instructors using Web-supported instruction.

The model includes 44 benefit components and 23 cost components in six dimensions:

1. Increasing efficiency of teaching and learning processes

This dimension includes cost reduction through time saving as a result of implementing the Internet (e.g., reducing students' library time, saving classroom costs).

2. Improving instruction quality

This dimension refers to improving the effectiveness of pedagogical aspects by enriching the learning environment (e.g., using simulations, asynchronous communication among students).

3. Improving affective aspects

This dimension includes increasing students' and instructors' motivation, interest, selfconfidence, and satisfaction.

\section{Knowledge management improvement}

Management system allows effective knowledge organization as well as greater collaboration, information exchange, and sharing of resources and instructional materials (e.g., using the course Web site over the years or sharing it with other instructors).

5. Infrastructure costs

Technological infrastructure costs, such as central infrastructure and equipment costs (e.g., servers, software, and communication) and operational infrastructure costs, such as institute support centre, training, workshops, and continuous technological and pedagogical support (i.e., preliminary and ongoing support for faculty and students and implementation costs).

6. Instruction costs

Course development and preparation, costs of curriculum development and course production these costs are reflected in the amount of instructional materials embedded in the Web site and instruction/learning costs, including assessment time and interaction time with students.

A computational analyzer was developed in order to translate the 67 cost and benefit components of the model into quantitative values. For each one of the components, computational functions $(\mathrm{Y}=\mathrm{f}(\mathrm{X}) * \mathrm{M})$ are defined. These functions calculate quantitative values for each of the three main actors involved in the learning process: students, instructors, and the academic institution's policymakers. The indicators $\left(\mathrm{X}\left\{\mathrm{x}_{1} \ldots \mathrm{x}_{93}\right\}\right)$ are extracted from the sites' Web-logs; they are independent variables that characterize the course, the course Web site, the Web-supported teaching processes, and their use by students. The cost effectiveness parameters $\left(M=\left\{m_{1} \ldots m_{82}\right\}\right)$ translate the costs and benefits derived from the independent variables into a quantitative measure in terms of four different "coins" on a cost effectiveness scale. The computational mechanism is the collection of all functions. The indicators (X) and parameters (M) constitute the input of this mechanism; the 
computational mechanism (through the functions) processes the data to produce the desired output. The output consists of the cost effectiveness values for each of the three actors in terms of four different coins: efficiency coins for money (\$) and time (hours), quality coins (Q) for improving instruction and learning quality, affective coins (A) for improving affective aspects, and knowledge management coins (KM) for facilitating knowledge management.

Although the development process is tedious and includes a very large number of definitions (67 components, 93 indicators, 82 parameters, and 108 functions), activating the analyzer is rather simple. The indicators and parameters are represented in two spreadsheet input files; all the definitions of the functions are represented in a third file; and the fourth file represents the cost effectiveness values yielded by the calculations. The amount of coins received in these dimensions indicates the effectiveness level found. Anyone who uses the analyzer can insert the input data manually or produce them from the Web-supported shell. He or she can also define the parameters for each measurement according to case-sensitive predispositions. Then the computational analyzer is activated and the computational mechanism processes the data to produce the output.

The cost effectiveness analyzer was implemented in 3,453 Virtual TAU courses during the academic year 2006-7 in order to estimate the cost effectiveness of large-scale, campus-wide, Web-supported instruction processes. Course enrollment was comprised of 23,352 students and 1,850 instructors. Table 4 presents a summary of the cost and benefit analysis (more details are available in Cohen, 2009).

Table 4

Summary of the Cost and Benefit Analysis

\begin{tabular}{|c|c|c|c|c|}
\hline Costs and Benefits & Coins & $\begin{array}{l}\text { Students } \\
N=23,352\end{array}$ & $\begin{array}{l}\text { Instructors } \\
N=1,850\end{array}$ & University \\
\hline Infrastructure costs & $\$$ & --- & --- & $\$ 240,000$ \\
\hline Instruction costs & $\$$ & $\$ 60,000$ & $\$ 1,050,000$ & --- \\
\hline Efficiency increase & $\$$ & $\$ 10,740,000$ & $\$ 500,000$ & $\$ 20,000$ \\
\hline Quality improvement & Quality Coins (Q) & $35,000,000 \mathrm{Q}$ & $4,100,000 \mathrm{Q}$ & --- \\
\hline Affective aspects & Affective Coins (A) & $27,000,000 \mathrm{~A}$ & $2,300,000 \mathrm{~A}$ & $29,300,000 \mathrm{~A}$ \\
\hline Knowledge management & KM Coins & $120,000 \mathrm{KM}$ & $650,000 \mathrm{KM}$ & $115,000 \mathrm{KM}$ \\
\hline
\end{tabular}

$1 \$=3.6$ New Israeli Shekel (NIS)

From these data we can glean the following observations concerning TAU:

- The total direct cost of integrating Web sites in academic instruction was about $\$ 1,350,000$. About 78\% of this sum went into the development and implementation of the online instruction by the instructors, including the time invested in interaction with students and assessment (instructor time was converted to money, $1_{\text {hour }}=\$ 30$ ). About $18 \%$ of the costs were invested by the university in the technological and operational infrastructure, and about $4 \%$ was spent by the students mostly for printing the electronic learning materials, rather than obtaining handouts from 
their instructors. It is not surprising that the instructors and the university are the main investors while the students reap most benefits.

- Increased efficiency of teaching and learning processes was measured by means of 28 computational functions. About $\$ 10,740,000$ was saved by students and a further $\$ 500,000$ by instructors. About $95 \%$ of the total saving belongs to the students as a result of electronic content Page | 13 consumption efficiency, getting/delivering electronic announcements, performing exercises online, posting papers and assignments on the Web, and saving copying/printing costs.

- Improved instruction quality was measured by means of 24 computational functions. Quality coins (Q) were calculated for various pedagogical activities (e.g., one viewing of online paper $=2$ $\mathrm{Q}$; activating a simulation $=5 \mathrm{Q}$; viewing lesson recordings $=4 \mathrm{Q}$; one forum posting $=1 \mathrm{Q}$, etc.). In the year 2006-07, about 35,000,000 Q were awarded for student learning as a result of activity based on interpersonal communication and various content knowledge representations, in particular for self-exercises accompanied by immediate feedback that enables individual learning at a personal pace. The fact that the instructor received over 4,000,000 Q of quality coins (e.g., one posting of a reply message to a student in a forum $=0.5 \mathrm{Q}$ ), suggested improved instruction as a result of intensive Web site use, interpersonal communication, and production of student activity reports, which made it possible to supervise students' learning.

- Improved affective aspects, e.g., satisfaction, were measured through 15 computational functions. Students and instructors received a very high value of affective coins (A) (27,000,000 A for students and 2,300,000 A for instructors), reflecting satisfaction as a result of simplicity of use; interactivity; immediate feedback; flexible learning; and interaction between lecturer and students. The university scored a very high affective benefit (29,300,000 A) for the prestige gain that was the result of offering technology-based instruction.

- Knowledge management improvement was measured through five computational functions. The students and the university got knowledge management benefits from working with the course Web site (about 120,000 KM knowledge management coins for students and 115,000 KM for the university). But the great winners were the instructors, who received 650,000 KM for effective knowledge organization (e.g., greater collaboration and sharing among instructors and reusing materials over the years).

Our cost effectiveness model demonstrates that quantifying the cost and benefit components of Websupported instruction is possible. It uses empirical data taken from students' and instructors' Weblogs and provides quantitative analysis of the pedagogical benefits of Internet use. Finally, it enables decision-makers to quantify cost and benefit on both the single course and the campus-wide level. This model and analyzer addresses the need for assessing Web-supported academic instruction and blended learning (rather than distance learning only).

\section{Conclusions}

This paper described some of the institutional and the pedagogical aspects of Virtual TAU, a campuswide project aimed at integrating the Internet into the academic instruction in Tel-Aviv University. Two main preliminary and apparently contrasting conclusions can be drawn. The first is related to the impressive pace at which the Internet has been introduced in the university's academic instruction. 
Beyond any expectation, many instructors adopted the technology in a relatively short time, triggering the comprehensive diffusion of Web-supported academic instruction throughout the campus and at all academic levels. Some instructors, although not many, demonstrate impressive use of the Web by implementing newly emerging pedagogies. The other contrasting conclusion relates to the still limited pedagogical range of the activities the rest of the instructors used. Most of these activities are contentrather than communication-oriented. Instructors largely vary in the extent and ways they exploit the Web for instruction; however, overwhelmingly, it is still being used at the trivial content-based level.

The data from the research presented in this study as well as from the design and empirical implementation of our cost-effectiveness model on TAU courses suggest that the process of integrating Web-supported academic instruction campus-wide is extremely complex. Nevertheless, we are seeing the first signs of how the Web is being used and of its potential: it is heavily dependent on the initiative and input of TAU instructors but provides many benefits in terms of students' learning processes, instruction, and the university's prestige. It is clear that we are only at the beginning of a process which, with more effort, will significantly change and improve instruction at the university. 


\section{References}

Acrich, T. (2005). Case study of "Introduction to Cell Biology" technological instruction aided course. Unpublished master's thesis. School of Education, Tel Aviv University. (Hebrew).

Allen, E. \& Seaman, J. (2005). Growing by degrees: Online education in the United States.

Sloan Consortium (Sloan-C) [online]. Available at: http://www.sloanc.org/resources/growing by degrees.pdf

Allen, E. \& Seaman, J.(2006). Making the grade: Online education in the United States. Sloan Consortium (Sloan-C) [online].

Available at: http://www.sloan-c.org/publications/survey/index.asp

Allen, E. \& Seaman, J. \& Garrett, R. (2007). Blending in: The extent and promise of blended education in the United States. Sloan Consortium (Sloan-C) [online]. Available at: http://www.sloan-c.org/publications/survey/pdf/Blending_In.pdf

Bass, F. (1969). A new product growth model for consumer durables. Management Science, 15(5), 215-227.

Bates, A.W. (2000). Managing technological change. San Francisco, Ca. Jossey-Bass Inc.

Bonk, C. J., \& Graham, C. R. (2006). Handbook of blended learning: Global perspectives, local designs. San Francisco, CA: Pfeiffer.

Cohen, A. (2009). A cost effectiveness model for Web-supported academic instruction: Development, validation, and implementation. Unpublished doctoral thesis, School of Education, Tel Aviv University. (Hebrew).

Cohen, A., \& Nachmias, R. (2006). A quantitative cost effectiveness model for Websupported academic instruction. Internet and Higher Education, 9, 81-90.

Cohen, A., \& Nachmias, R. (2008). A case study of implementing a cost effectiveness analyzer for Web-supported academic instruction: An example from life science. Paper presented at EDEN 08 Annual Conference, Lisbon.

Collis, B., \& Moonen, J. (2001). Flexible learning in a digital world: Experiences and expectations. London: Kogan Page.

Elstein, Y. (2004). Why don't they join the bandwagon or: Obstacles and incentives influencing higher education faculty in integrating Web-based teaching in their courses. Unpublished master's thesis, School of Education, Tel Aviv University. (Hebrew).

Nachmias, R. (2002). Research framework for the study of a campus-wide Web-based academic instruction project. The Internet and Higher Education, 5(3), 213-229. 
Nachmias, R., Ram, J., \& Mioduser, D. (2006). Virtual TAU: The study of a campus-wide implementation of blended learning in Tel- Aviv University. In C.J. Bonk \& C.R. Graham. (Eds), Handbook of blended learning: Global perspectives, local designs (pp 374-386). San Francisco, CA: Pfeiffer.

Nachmias, R., \& Segev, L. (2003). Students' use of content in Web-supported academic courses. Internet and Higher Education, 6, 145-157.

Rogers, E.M. (1995). Diffusion of innovation (4th ed.). New York: Free Press.

Rogers, E.M. (2003). Diffusion of innovation (5th ed.). New York: Free Press.

Shemla, A. (2008). Pedagogical aspects of Web integration in academic instruction. Unpublished doctoral thesis, School of Education, Tel Aviv University (Hebrew).

Shemla, A., Nachmias, R. (2007). Current state of Web-supported courses at Tel Aviv University. International Journal on E-Learning. 6(2), 235-264.

Soffer, T. (2006). Diffusion of Web-supported academic instruction. Unpublished doctoral Thesis, School of Education, Tel Aviv University. (Hebrew).

Soffer, T., \& Nachmias, R. (2008). Diffusion of Web-supported learning in higher educationThe TAU case. Unpublished manuscript, Tel Aviv University.

Steimberg, Y., Ram, J., Nachmias, R., \& Eshel, A. (2006). An online discussion for supporting students in preparation for a test. Journal of Asynchronous Learning Networks, 10(45). 117-128.

Steimberg, Y., Ram, J., Nachmias, R., \& Israeli, R. (2008) Redesign of statistics course: A comparative study of fully online, hybrid and face-to-face modes. Paper presented at EDEN 08 Annual Conference. Lisbon.

Tikochinsky, M. (2002). Students' participation patterns in Web-based academic forums. Unpublished master's thesis, School of Education, Tel Aviv University (Hebrew). 